\title{
Assessment of Hip Translation In Vivo in Patients With Femoracetabular Impingement Syndrome Using 3-Dimensional Computed Tomography
}

\author{
Gregory L. Cvetanovich, M.D., Edward C. Beck, M.D., M.P.H., Peter N. Chalmers, M.D., \\ Alejandro A. Espinoza Orías, Ph.D., Michael D. Stover, M.D., Nozomu Inoue, M.D., Ph.D., \\ and Shane J. Nho, M.D., M.S.
}

\begin{abstract}
Purpose: To determine the 3-dimensional (3D) in vivo hip translation in patients with symptomatic femoroacetabular impingement syndrome (FAIS) using 3D computed tomography (CT) models with the hip in neutral and FABER (flexion, abduction, and the external rotation) positions and to identify patient predictors associated with the degree of hip translation. Methods: Seventy-eight patients with FAIS and cam lesions underwent CT scans in neutral and FABER positions. Demographics including age, sex, and body mass index (BMI) were recorded for each patient. The cam deformity was characterized both in plain x-ray film and 3D. Translation between both positions was calculated using a validated high-precision 3D-3D registration technique. Univariate and multivariate regression analyses sought factors correlated with translation. Results: The mean age of the patients included in the analysis was $36.3 \pm 9.2$ years, with $51 \%$ of the study group being female. The mean 3D femoral head center translation was $0.84 \pm 0.37 \mathrm{~mm}$, decomposed into vectors on standard anatomical directions as $0.13 \pm 0.58 \mathrm{~mm}$ medial, $0.10 \pm 0.54 \mathrm{~mm}$ posterior, and $0.08 \pm 0.46 \mathrm{~mm}$ inferior. Multivariate analysis demonstrated that total translation was associated with larger alpha angles $(\beta=0.014 ; 95 \%$ confidence interval $[\mathrm{CI}]$ 0.003-0.024; $P=.013)$, and greater BMI $(\beta=0.033 ; 95 \%$ CI 0.001-0.065; $P=.042)$. Furthermore, posterior-inferior translation was associated with BMI $(\beta=0.032 ; 95 \%$ CI $0.003-0.061 ; P=.031)$, whereas medial-lateral translation is associated with the female sex $(\beta=0.388 ; 95 \%$ CI $0.124-0.634 ; P=.002)$, and smaller head radius $(\beta=-0.068 ; 95 \% \mathrm{CI}-0.128$ to $-0.007 ; P=.029)$. Conclusions: As a provocative maneuver, FABER positioning in patients with FAIS resulted in an average measurable translation of the femoral head center in the posterior, medial, and inferior direction. Factors including sex, BMI, and alpha angle predicted the degree of translation. Clinical Relevance: The current study demonstrates that there is measurable hip translation between the neutral and FABER positions in patients with symptomatic FAIS, which may cause hip microinstability. Furthermore, the study found an association between hip translation and both modifiable and nonmodifiable factors. This may indicate the need for more comprehensive preoperative surgical planning, intraoperative dynamic examination of the hip, and consideration of capsular plication in certain patients.
\end{abstract}

From the Department of Orthopedic Surgery, Ohio State University Wexner Medical Center, Columbus, Ohio (G.L.C); Department of Orthopedic Surgery, Wake Forest Baptist Health, Winston-Salem, North Carolina (E.C.B.); Department of Orthopedic Surgery, University of Utah, Salt Lake City, Utah (P.N.C.); Department of Orthopedic Surgery, Rush University Medical Center, Chicago, Illinois (A.A.E.O., N.I., S.J.N.); and Department of Orthopedic Surgery, Northwestern University Medical Center, Chicago, Illinois (M.D.S.), U.S.A.

The authors report the following potential conflicts of interest or sources of funding: This study was supported in part by NIH/NCCIH R01 AT006692. G.L.C. discloses education payments from Smith $\theta$ Nephew and Arthrex. S.J.N. reports nonfinancial support from Allosource, other from the American Journal of Orthopedics, other from the American Orthopaedic Society for Sports Medicine, nonfinancial support from Arthrex, other from the Arthroscopy Association of North America, nonfinancial support from
Athletico, nonfinancial support from DJ Orthopaedics, nonfinancial support from Linvatec, nonfinancial support from Miomed, personal fees from Ossur, nonfinancial support from Smith $\theta$ Nephew, personal fees and nonfinancial support from Springer, and nonfinancial support from Stryker, outside the submitted work. Full ICMJE author disclosure forms are available for this article online, as supplementary material.

Received June 18, 2015; accepted December 12, 2019.

Address correspondence to Shane J. Nho, M.D., M.S., 1611 W Harrison St., Suite 200, Chicago, IL 60612.E-mail:nho.research@rushortho.com

(C) 2020 THE AUTHORS. Published by Elsevier Inc. on behalf of the Arthroscopy Association of North America. This is an open access article under the CC BY-NC-ND license (http://creativecommons.org/licenses/by-nc-nd/4.0/). 2666-061X/15543

https://doi.org/10.1016/j.asmr.2019.12.002 
$\mathbf{F}$ emoroacetabular impingement syndrome (FAIS) has been established as a common cause of hip pain in young patients and also has been implicated in the secondary development of hip osteoarthritis. ${ }^{1-3}$ The condition can exist in 3 main variations of morphologic impingement: cam impingement resulting from decreased concavity of the femoral head-neck junction, pincer impingement from acetabular overcoverage, and a combination of both, which is the more common presentation. ${ }^{1,2,4}$ From a biomechanical perspective, this impingement results in repetitive lowimpact loading, with peaks occurring during flexion and internal rotation, ${ }^{5}$ producing clinical symptoms that are often reproducible during physical examination by placing the symptomatic hip in flexion, abduction, and the external rotation (FABER) position. ${ }^{6}$

Although the hip is typically thought of as a ball and socket joint with purely rotational motion, hip translation has been documented both in cadaveric models and in vivo. ${ }^{7-12}$ Previous cadaveric studies have suggested that translation is increased by damage to the hip capsule, ligaments, and labrum. ${ }^{9,13}$ There are a growing number of reports in the literature of joint kinematics analysis during in vivo clinical examination maneuvers, ${ }^{8,14,15}$ which have quantified hip translation between different hip positions using computed tomography $(\mathrm{CT})^{15}$ or magnetic resonance imaging (MRI), ${ }^{8,14}$ but many of these focus solely on the dysplastic hip without FAIS.

Hip translation and microinstability has been recently recognized in FAS and thought to be directly caused by the subtle anatomical bony abnormalities leading to soft-tissue damage. ${ }^{16-18}$ However, the literature is limited on quantifying hip translation in patients with FAIS when placing the symptomatic hip into impingement. Improved understanding of hip translation in the setting of FAIS could have implications for understanding the role of microinstability in patient symptoms and for both for capsular management and surgical deformity resection planning in the setting of hip arthroscopy. The purposes of this study were to determine the 3-dimensional (3D) in vivo hip translation in patients with symptomatic FAIS using 3D CT models with the hip in neutral and FABER positions and to identify patient predictors associated with the degree of hip translation. We hypothesized that FAIS deformity morphology would be correlated with 3D hip translation and that it may be associated with age and sex.

\section{Methods}

\section{Patient Selection}

Patients with symptomatic FAIS were identified using an electronic medical record database at our institution. Patient informed consent and institutional review board approval was obtained for this study. Patients were included if they underwent primary hip arthroscopy performed by the senior author (S.J.N.) for symptomatic FAIS between January 2010 and March 2013. Exclusion criteria included previous ipsilateral hip surgery or incomplete plain radiographs and CT imaging. As part of their normal preoperative work-up, patients underwent CT scans in both a neutral position and in a FABER position of flexion, abduction, and external rotation (FABER). A positive FABER test was defined as asymmetry in the distance between the lateral knee and the exam table between the injured hip and the noninjured hip. ${ }^{19}$ Patient demographics were recorded, including side of symptomatic hip (right or left), age at time of surgery, body mass index (BMI), and sex. Plain radiographs, including anteroposterior, false profile, and Dunn $45^{\circ}$ views, were obtained as part of the patients' normal preoperative evaluation and analyzed for Tönnis grade, Tönnis angle alpha angle, and lateral center edge angle. ${ }^{20}$

\section{Creation of 3D CT Models}

Preoperative CTs $(0.625$-mm slices, no spacing, $512 \times$ 512 matrix; GE Brightspeed, Waukesha, WI) of the affected hip in both neutral and FABER positions were imported in Digital Imaging and Communications in Medicine format and segmented using a commercially available 3D-reconstruction software (Mimics 17 Research; Materialise, Leuven, Belgium), and 3D femoral and acetabular models in each position for each patient were created (Fig 1). The femoral head center, femoral head radius, and 3D cam deformity height and volume were calculated using the neutral CT hip model with a custom-written program (Visual $\mathrm{C}++$; Microsoft Corporation, Redmond, WA) as previously described (Fig 2). ${ }^{21,22}$

\section{D-3D Registration Technique to Measure Spatial Rotation and Translation}

Movements of the proximal femur and acetabulum were measured by 3D-3D registration of the $3 \mathrm{D}$ models of individual bones at the neutral and FABER positions using the validated volume merge method as the 3D-3D registration technique (accuracy; $0.1 \mathrm{~mm}$ in translation, $0.2^{\circ}$ in rotation). ${ }^{23}$ In the volume merge method, each bone in the neutral position (the moving bone) was virtually rotated around the femoral head center and translated toward the same bone in a FABER position (the stationary target). These rotations and translations of the bone were conducted with $0.05^{\circ}$ and $0.05-\mathrm{mm}$ increments, respectively, until the maximum degree of volume merging was obtained between the moving bone and the stationary target in the FABER position. Rotations of the femur and translations of the femoral head center from the neutral position to FABER position were calculated based on a local coordinate system 
Fig 1. Illustration demonstrating 3-dimensional computed tomographic right-sided hip models at neutral (left) and FABER (right) positions. (FABER, flexion, abduction, and the external rotation.)

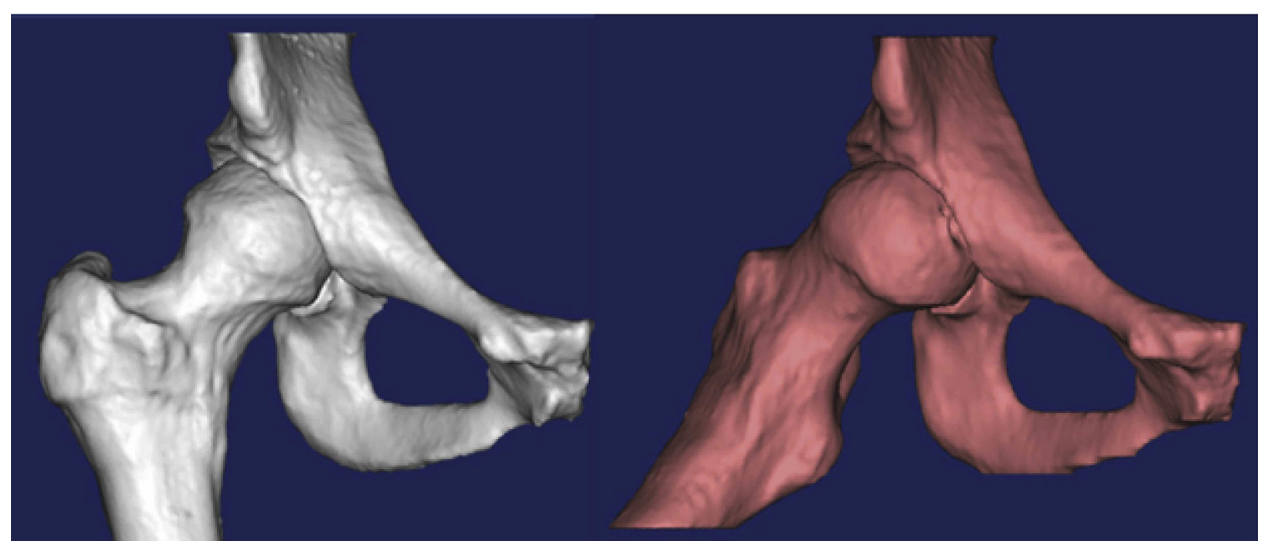

centered at the femoral head centroid at the neutral position (Fig 3). The axes of the local coordinates coincide with anatomical axes so that the directions of the rotation and translation correspond to the clinical notation.

\section{Statistical Analysis}

Descriptive statistics are presented as mean \pm standard deviation and range. Univariate and stepwise multivariate regression analyses were performed to evaluate whether patient demographics (i.e., age, sex, and body mass index [BMI]), Tönnis grade, and FAIS morphology (alpha angle, lateral center edge angle, Tönnis angle, cam deformity height, and cam deformity volume) were associated with hip translation. Significance was set at $P<.05$. All analyses were carried out with SPSS Statistics, version 22 (IBM Corp., Armonk, NY).

\section{Statistical Power}

Considering the error margin in the measurements of $0.1 \mathrm{~mm}$, a sample size calculation in SPSS Sample Power 3 (IBM Corp.) showed that for the study to effectively estimate a $95 \%$ likelihood of the sample mean falling within the established error margin, a sample size of $\mathrm{n}=56$ subjects is required. Thus, the number of enrolled subjects in this study amply satisfies the requirement of $95 \%$ power.

\section{Results}

\section{Demographics and Radiographic Measurements}

Of the 251 patients with symptomatic FAIS in the retrospective database, 78 met the exclusion criteria and were included in the final analysis (Fig 4). There were 40 female $(51 \%)$ and 38 male $(49 \%)$ patients; 36 left hips $(46 \%)$ and 42 right hips (54\%). Patient age was $36.3 \pm 9.2$ years, and BMI was $24.2 \pm 3.5$ (Table 1 ). Tönnis grade was 2 in 2 patients $(3 \%), 1$ in 23 patients $(29 \%)$, and 0 in 53 patients $(68 \%)$. Average alpha angle was $61.9 \pm 10.6^{\circ}$, lateral center edge angle was $34.1 \pm 6.6^{\circ}$, and Tönnis angle was $2.7 \pm 3.3^{\circ}$.

\section{Characterization of the Cam Deformity}

Based on the 3D measurements, the mean overall cam deformity height was $1.3 \pm 0.8 \mathrm{~mm}$, (range: -0.44

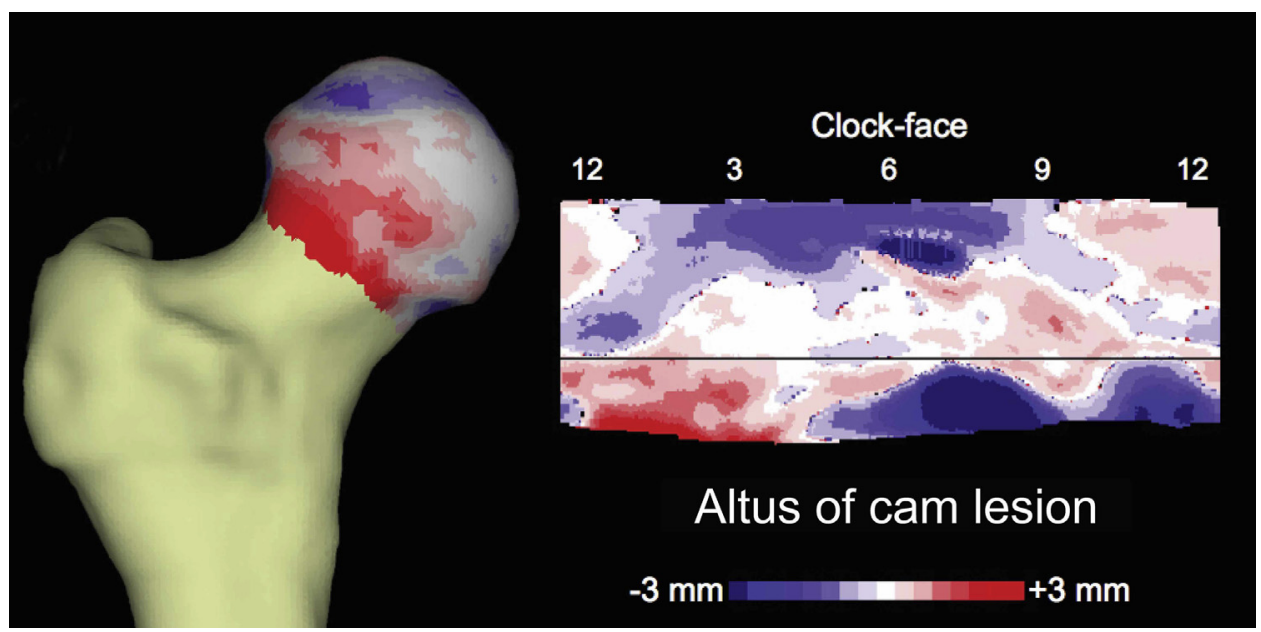

Fig 2. A global view of the rightsided femoral head superimposed with the color code representing the amount of bony protrusion (red) or indentation (blue) and an atlas view of a planar projection of the globe for calculation of cam deformity height and volume. 


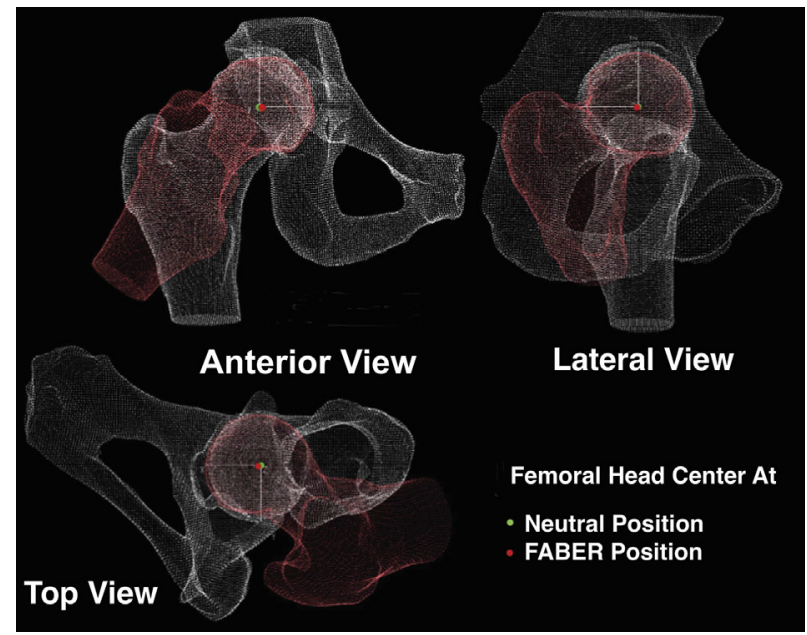

Fig 3. Image demonstrating the $3 \mathrm{D}-3 \mathrm{D}$ registration technique for calculation of translation of a right-sided femoral head center from the neutral position (green dot) to the FABER position (red dot). (FABER, flexion, abduction, and the external rotation.)

to $2.88 \mathrm{~mm}$ ), and the mean cam deformity volume was $321.1 \pm 423.1 \mathrm{~mm}^{3}$ (range -71 to $2201 \mathrm{~mm}^{3}$ ). The negative signs identify a depression instead of a protuberance with respect to the femoral head surface.

\section{Hip Rotation}

Mean overall rotation of the hip joint from the neutral position to FABER positions was $33.1 \pm 7.5^{\circ}$ (range $13.0-50.6^{\circ}$ ) of flexion, $6.3 \pm 5.0^{\circ}$ (range 0.05$20.0^{\circ}$ ) of abduction, and $55.4 \pm 17.7^{\circ}$ (range 15.5$\left.90.6^{\circ}\right)$ of external rotation.

\section{D Hip Translation}

Mean overall 3D femoral head center translation between the neutral and FABER positions was $0.84 \pm$ $0.37 \mathrm{~mm}$ (range $0.25-1.88 \mathrm{~mm}$ ). The direction of 3D translation in FABER position compared with neutral was $0.13 \pm 0.58 \mathrm{~mm}$ medial, $0.10 \pm 0.54 \mathrm{~mm}$ posterior, and $0.08 \pm 0.46 \mathrm{~mm}$ inferior. Overall, $29 \%$ of patients (23 of 78) had total translation greater than $1 \mathrm{~mm}$.

\section{Multivariate Regression}

Stepwise multivariate regression for each translation is summarized in Table 2. For medial-lateral translation, only sex remained significant $(\beta=0.388 ; 95 \%$ confidence interval $[\mathrm{CI}] 0.124-0.634 ; P=.002)$, with female sex having a linear association. For superior-inferior translation, only BMI remained significant ( $\beta=0.032 ; 95 \%$ CI $0.003-0.061 ; P=.031)$ was significant. Lastly, both alpha angle $(\beta=0.014 ; 95 \%$ CI $0.003-0.024 ; P=.013)$ and BMI $(\beta=0.033 ; 95 \%$ CI 0.001-0.065; $P=.042$ ) demonstrated a linear association with total transformation. Of note, none of the variables demonstrated a linear association with translation in the anterior-posterior plane.

\section{Discussion}

The main finding of this study was that there is a measurable hip translation between the neutral and FABER positions in patients with symptomatic FAIS, with a mean translation of $0.84 \mathrm{~mm}$. On average, translation was in the posterior-inferior-medial direction, but the direction of translation varied among patients. On multivariate analysis, female sex had a linear association with medial-lateral translation, BMI had a linear association with superior-inferior translation, and BMI and alpha angle had a linear association with total translation. This study is one of first to evaluate in vivo 3D hip translation between the neutral and FABER positions exclusively in patients with symptomatic FAIS using a high-precision 3D-3D CT registration technique.

There have been earlier studies addressing hip translation in FAIS patients. Kapron et al. ${ }^{15}$ used CT and dual-fluoroscopy motion analysis in an exploratory study to evaluate joint kinematics in 3 subjects who were to undergo hip arthroscopy for symptomatic FAI, who also were of varied characteristics: one pistol-grip deformity, the second one with acetabuli protrusion, and the third with mixed-FAIS showing acetabular overcoverage, a cam deformity, and pincer groove in the anterofemoral neck. Our results are within the range measured by Kapron et al. Although that study showed feasibility of the dual-fluoroscopy approach in actual patients, it has some limitations, namely the unnecessary ionizing radiation exposure of the examiner, and the fact that the small sample size did not allow analysis of relationships between patient and deformity characteristics with hip translation. The latter also highlights the need for a FAIS classification scheme that can allow clinicians and researchers alike to better

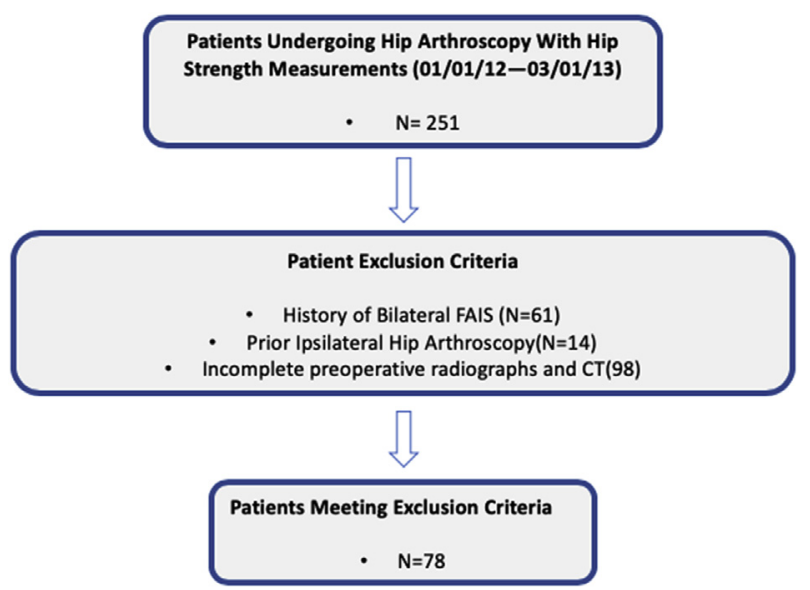

Fig 4. Diagram indicating the number of patients meeting inclusion criteria from the study, and the number of patients meeting the inclusion criteria that were included in the final analysis. (CT, computed tomography; FAIS, femoroacetabular impingement syndrome.) 
Table 1. Demographic and Radiographic Parameters for Study Participants

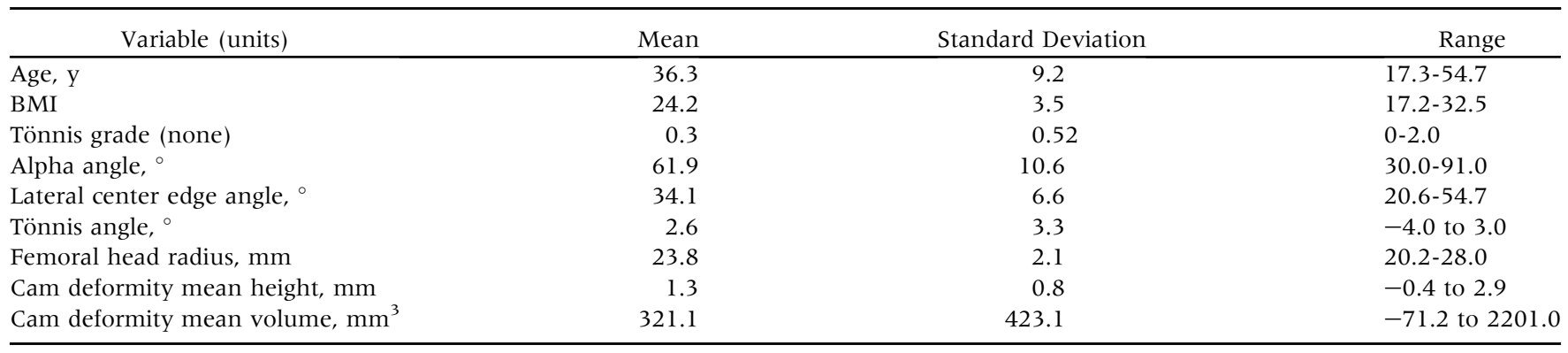

correlate the size and position of the deformity to the kinematic alterations they produce. It is difficult to repeat the same rotation, notion profile, but as long as it stays within the motion envelope it should be deemed repeatable.

Akiyama et al. ${ }^{7,8}$ used in vivo 3D MRI to evaluate normal and dysplastic hips in neutral, $45^{\circ}$ flexion, $15^{\circ}$ extension, and FABER position. For the FABER position, the femoral head center translated postero-infero-medially by $3.16 \pm 0.88 \mathrm{~mm}$ for normal male hips, $3.25 \pm 0.73 \mathrm{~mm}$ for normal female hips, and $4.00 \pm 1.20 \mathrm{~mm}$ for dysplastic hips. Dysplastic hips translated significantly more than normal female hips but not normal male hips, and multiple regression showed femoral head sphericity and acetabular sphericity were associated with translation in the FABER position. We found less translation compared with these studies, which could be related to our patient population of patients with FAIS having less translation than dysplastic hips and to greater accuracy of CT compared with MRI for quantifying translation. ${ }^{8,24}$ Our direction of translation from neutral to FABER position was the same as identified Akiyama et al. in the postero-medial-inferior direction. In addition, several studies have quantified the in vivo difference in femoral head center of rotation and acetabular center of rotation for dysplastic hips and hips with Legg-Calvé-Perthes disease, ${ }^{25-27}$ but these studies differ from the present analysis by not addressing translation of the femoral head in different hip positions.

Swiss researchers have investigated in vivo hip translation in dancers performing ballet maneuvers. Charbonnier et al. ${ }^{10}$ used an optical tracking motion capture system to determine hip translation in dancers in various ballet positions, finding a translation of $5.14 \pm 1.28 \mathrm{~mm}$. Gilles et al. ${ }^{14}$ reported translation of $2.12 \pm 0.79 \mathrm{~mm}$ without a preferred translation direction in professional female dancers performing the splits with an MRI and surface registration technique. Similarly, Duthon et al. ${ }^{28}$ performed MRI in neutral position and while performing the splits, finding mean translation of $2.05 \mathrm{~mm}$, although no preferred direction was observed and no correlation with patient symptoms or radiographic FAIS parameters was detected. To the best of our knowledge, our study is the first to use 3D CT to quantify native hip translation in different hip positions and the first to assess translation in a large group of patients with clinical FAIS. Our use of CT results in superior bony detail and a more accurate assessment of translation than previous literature with motion capture or MRI, with our methodology's accuracy of $0.1 \mathrm{~mm}$ being superior to reported translation accuracy from previous MRI-based and motion-capture studies of approximately $0.5 \mathrm{~mm} .^{7,8,10,14}$ Our hip translation values were lower than those observed in dancers, likely related to a greater amount of translation for extreme dancing positions compared with our FABER position. In addition, dancers would be likely to have greater ligamentous laxity and hypermobility, leading to greater hip translation than our population of symptomatic patients with FAIS. ${ }^{29-31}$ Our CT also was performed in a static FABER position, which could have less associated hip translation than active dance maneuvers.

The current study found significant linear associations between patient demographic and radiographic factors and translation in the medial-lateral and the superior-inferior directions between the neutral and FABER positions. The regression analysis demonstrated that medial translation was associated with female sex, and smaller femoral head radius, whereas greater BMI had a linear relationship with superior-inferior and

Table 2. Results of Multivariate Linear Regression Analysis

\begin{tabular}{lrrrr}
\hline & $\beta$ Coefficient & $95 \%$ CI for $\beta$ & $P$ Value \\
\hline $\begin{array}{l}\text { Medial-lateral translation } \\
\quad \text { Sex }\end{array}$ & 0.388 & 0.124 & 0.634 & .002 \\
$\quad$ Head radius & -0.068 & -0.128 & -0.007 & .029 \\
$\begin{array}{l}\text { Posterior-inferior translation } \\
\quad \text { BMI }\end{array}$ & 0.032 & 0.003 & 0.061 & .031 \\
$\quad \begin{array}{l}\text { Total transformation } \\
\quad \text { Alpha angle }\end{array}$ & 0.014 & 0.003 & 0.024 & .013 \\
$\quad$ BMI & 0.033 & 0.001 & 0.065 & .042 \\
\hline
\end{tabular}

BMI, body mass index; CI, confidence interval. 
total translation. Previous clinical studies have demonstrated that female patients and those with greater BMI have lower reported functional scores and greater pain ${ }^{32,33}$; however, the literature is extremely limited when evaluating the effect of sex and BMI on hip kinematics. In addition, the current study found a linear association between larger alpha angle and total translation. Kalisvaart and Safran ${ }^{34}$ discussed in their review article how repetitive forces and anatomic pathology including pincer and cam deformity can result in increased translation of the femoral head relative to the acetabulum, ultimately leading to symptomatic him microstability. It is possible that the size of the alpha angle is directly correlated to the level of translation and microinstability, as bony impingement will occur at earlier in the range of hip motion in hips with larger cam lesions. Clinical studies confirm have confirmed this by observing that patients with larger cam lesions report greater pain at lower ranges of motion. ${ }^{35}$

Synthesizing our findings with the previous in vivo hip translation literature, we propose that hip translation depends on a combination of osseous factors, soft-tissue laxity, and hip position. Osseous factors promoting greater hip translation include poor acetabular coverage in the setting of acetabular dysplasia and larger alpha angles. Soft-tissue laxity promotes greater translation, which likely applies to dancers and some female patients. More extreme hip positions promote greater translation, such as those identified in dance maneuvers. We hypothesize that hip translation would be increased in patients with hip microinstability related to patient joint hypermobility or iatrogenic capsular insufficiency in the postarthroscopy setting. Cadaveric studies suggest that translation is increased by damage to the hip capsule, ligaments, and labrum. 9,11-13,36-40 Further in vivo studies are warranted using other maneuvers and a control population to examine the degree of translation in other hip positions.

\section{Limitations}

There are several limitations in this study that should be addressed. First, images were obtained in the neutral and FABER positions only, which was obtained as a normal part of the patients' preoperative imaging before hip arthroscopy. Positions other than FABER such as flexion, adduction, internal rotation (i.e., FADIR) might lead to greater bony impingement between the femoral cam deformity and the acetabulum in patients with symptomatic FAI and potentially to cause greater hip translation. Moreover, active maneuvers might result in greater translation than static FABER position, ${ }^{10,14,15,28}$ but CT of active maneuvers such as dance is not feasible with this methodology. In addition, the repeatability in the FABER position has not been assessed. Second, additional patient factors that might influence hip translation, such as the
Beighton hypermobility score, were not considered in this study. ${ }^{41}$ Fourth, our use of CT instead of MRI renders us unable to evaluate soft-tissue structures such as capsule and labrum. CT has the corresponding advantage of greater bony resolution and superior accuracy in determining translation. ${ }^{7,8,23,24,42-48}$ Fifth, the study did not examine acetabular morphology of each patient, including acetabular anteversion or retroversion, which could have an impact on femoral translation. In addition, while rotation of the femoral head was measured around the center of the head, the conchoid shape of the hip joint may have affected the changes in the center of rotation without translation. Sixth, the number of independent variables used to test multiple different translations without correction may have led to type I error. Lastly, the lack of a classification for the cam deformity does not allow our data to be used in a more efficient manner. The severity of the deformity is still not characterized in terms of functional outcomes such as kinematic parameters, and a better analysis could be done were this available.

\section{Conclusions}

As a provocative maneuver, FABER positioning in patients with FAIS resulted in an average measurable translation of the femoral head center in the posterior, medial, and inferior direction. Factors including sex, BMI, and alpha angle predicted the degree of translation.

\section{References}

1. Beck M, Kalhor M, Leunig M, Ganz R. Hip morphology influences the pattern of damage to the acetabular cartilage: Femoroacetabular impingement as a cause of early osteoarthritis of the hip. J Bone Joint Surg Br 2005;87: 1012-1018.

2. Ganz R, Parvizi J, Beck M, Leunig M, Notzli H, Siebenrock KA. Femoroacetabular impingement: A cause for osteoarthritis of the hip. Clin Orthop Relat Res 2003;417: 112-120.

3. Tanzer M, Noiseux N. Osseous abnormalities and early osteoarthritis: The role of hip impingement. Clin Orthop Relat Res 2004;429:170-177.

4. Allen D, Beaule PE, Ramadan O, Doucette S. Prevalence of associated deformities and hip pain in patients with cam-type femoroacetabular impingement. J Bone Joint Surg Br 2009;91:589-594.

5. Ito K, Minka MA 2nd, Leunig M, Werlen S, Ganz R. Femoroacetabular impingement and the cam-effect. A MRI-based quantitative anatomical study of the femoral head-neck offset. J Bone Joint Surg Br 2001;83:171-176.

6. Pacheco-Carrillo A, Medina-Porqueres I. Physical examination tests for the diagnosis of femoroacetabular impingement. A systematic review. Phys Ther Sport 2016;21:87-93.

7. Akiyama K, Sakai T, Koyanagi J, Yoshikawa H, Sugamoto K. Evaluation of translation in the normal and dysplastic hip using three-dimensional magnetic 
resonance imaging and voxel-based registration. Osteoarthritis Cartilage 2011;19:700-710.

8. Akiyama K, Sakai T, Koyanagi J, Yoshikawa H, Sugamoto K. In vivo hip joint contact distribution and bony impingement in normal and dysplastic human hips. J Orthop Res 2013;31:1611-1619.

9. Bayne CO, Stanley R, Simon P, et al. Effect of capsulotomy on hip stability - a consideration during hip arthroscopy. Am J Orthop (Belle Mead NJ) 2014;43: $160-165$.

10. Charbonnier C, Kolo FC, Duthon VB, et al. Assessment of congruence and impingement of the hip joint in professional ballet dancers: A motion capture study. Am J Sports Med 2011 ; 39:557-566.

11. Ito H, Song Y, Lindsey DP, Safran MR, Giori NJ. The proximal hip joint capsule and the zona orbicularis contribute to hip joint stability in distraction. J Orthop Res 2009;27:989-995.

12. Safran MR, Lopomo N, Zaffagnini S, et al. In vitro analysis of peri-articular soft tissues passive constraining effect on hip kinematics and joint stability. Knee Surg Sports Traumatol Arthrosc 2013;21:1655-1663.

13. Crawford MJ, Dy CJ, Alexander JW, et al. The 2007 Frank Stinchfield Award. The biomechanics of the hip labrum and the stability of the hip. Clin Orthop Relat Res 2007;465: 16-22.

14. Gilles B, Christophe FK, Magnenat-Thalmann N, et al. MRI-based assessment of hip joint translations. J Biomech 2009;42:1201-1205.

15. Kapron AL, Aoki SK, Peters CL, Anderson AE. In-vivo hip arthrokinematics during supine clinical exams: Application to the study of femoroacetabular impingement. J Biomech 2015;48:2879-2886.

16. Krych AJ, Thompson M, Larson CM, Byrd JW, Kelly BT. Is posterior hip instability associated with cam and pincer deformity? Clin Orthop Relat Res 2012;470:3390-3397.

17. Safran MR. Microinstability of the hip-gaining acceptance. J Am Acad Orthop Surg 2019;27:12-22.

18. Canham CD, Yen YM, Giordano BD. Does femoroacetabular impingement cause hip instability? A systematic review. Arthroscopy 2016;32:203-208.

19. Philippon M, Schenker M, Briggs K, Kuppersmith D. Femoroacetabular impingement in 45 professional athletes: Associated pathologies and return to sport following arthroscopic decompression. Knee Surg Sports Traumatol Arthrosc 2007;15:908-914.

20. Clohisy JC, Carlisle JC, Beaule PE, et al. A systematic approach to the plain radiographic evaluation of the young adult hip. J Bone Joint Surg Am 2008;90:47-66 (suppl 4).

21. Kang RW, Yanke AB, Espinoza Orias AA, Inoue N, Nho SJ. Emerging ideas: Novel 3-D quantification and classification of cam lesions in patients with femoroacetabular impingement. Clin Orthop Relat Res 2013;471:358-362.

22. Yanke AB, Khair MM, Stanley R, et al. Sex differences in patients with CAM deformities with femoroacetabular impingement: 3-dimensional computed tomographic quantification. Arthroscopy 2015;31:2301-2306.

23. Ochia RS, Inoue N, Renner SM, et al. Three-dimensional in vivo measurement of lumbar spine segmental motion. Spine (Phila Pa 1976) 2006;31:2073-2078.
24. Ishii T, Mukai Y, Hosono N, et al. Kinematics of the upper cervical spine in rotation: In vivo three-dimensional analysis. Spine (Phila Pa 1976) 2004;29:E139-E144.

25. Gose S, Sakai T, Shibata T, Murase T, Yoshikawa H, Sugamoto K. Morphometric analysis of acetabular dysplasia in cerebral palsy: Three-dimensional CT study. J Pediatr Orthop 2009;29:896-902.

26. Murphy SB, Kijewski PK, Millis MB, Harless A. Acetabular dysplasia in the adolescent and young adult. Clin Orthop Relat Res 1990;261:214-223.

27. Pienkowski D, Resig J, Talwalkar V, Tylkowski C. Novel three-dimensional MRI technique for study of cartilaginous hip surfaces in Legg-Calve-Perthes disease. J Orthop Res 2009;27:981-988.

28. Duthon VB, Charbonnier C, Kolo FC, et al. Correlation of clinical and magnetic resonance imaging findings in hips of elite female ballet dancers. Arthroscopy 2013;29: 411-419.

29. Bedi A, Galano G, Walsh C, Kelly BT. Capsular management during hip arthroscopy: From femoroacetabular impingement to instability. Arthroscopy 2011;27: 1720-1731.

30. Boykin RE, Anz AW, Bushnell BD, Kocher MS, Stubbs AJ, Philippon MJ. Hip instability. J Am Acad Orthop Surg $2011 ; 19: 340-349$.

31. Shu B, Safran MR. Hip instability: Anatomic and clinical considerations of traumatic and atraumatic instability. Clin Sports Med 2011;30:349-367.

32. Saltzman BM, Kuhns BD, Basques B, et al. The influence of body mass index on outcomes after hip arthroscopic surgery with capsular plication for the treatment of femoroacetabular impingement. Am J Sports Med 2017;45: 2303-2311.

33. Frank RM, Lee S, Bush-Joseph CA, Salata MJ, Mather RC 3rd, Nho SJ. Outcomes for hip arthroscopy according to sex and age: A comparative matched-group analysis. J Bone Joint Surg Am 2016;98:797-804.

34. Kalisvaart MM, Safran MR. Microinstability of the hip-it does exist: Etiology, diagnosis and treatment. J Hip Preserv Surg 2015;2:123-135.

35. Guler O, Isyar M, Karatas D, Ormeci T, Cerci H, Mahirogullari M. A retrospective analysis on the correlation between hip pain, physical examination findings, and alpha angle on MR images. J Orthop Surg Res 2016;11:140.

36. Abrams GD, Hart MA, Takami K, et al. Biomechanical evaluation of capsulotomy, capsulectomy, and capsular repair on hip rotation. Arthroscopy 2015;31:1511-1517.

37. Wuerz TH, Song SH, Grzybowski JS, et al. Capsulotomy size affects hip joint kinematic stability. Arthroscopy 2016;32:1571-1580.

38. Dy CJ, Thompson MT, Crawford MJ, Alexander JW, McCarthy JC, Noble PC. Tensile strain in the anterior part of the acetabular labrum during provocative maneuvering of the normal hip. J Bone Joint Surg Am 2008;90: 1464-1472.

39. van Arkel RJ, Amis AA, Cobb JP, Jeffers JR. The capsular ligaments provide more hip rotational restraint than the acetabular labrum and the ligamentum teres: An experimental study. Bone Joint J 2015;97-B:484-491. 
40. van Arkel RJ, Amis AA, Jeffers JR. The envelope of passive motion allowed by the capsular ligaments of the hip. J Biomech 2015;48:3803-3809.

41. Wolf JM, Cameron KL, Owens BD. Impact of joint laxity and hypermobility on the musculoskeletal system. J Am Acad Orthop Surg 2011;19:463-471.

42. Fujii R, Sakaura H, Mukai Y, et al. Kinematics of the lumbar spine in trunk rotation: In vivo three-dimensional analysis using magnetic resonance imaging. Eur Spine J 2007;16:1867-1874.

43. Fujimori T, Iwasaki M, Nagamoto Y, et al. Kinematics of the thoracic spine in trunk lateral bending: In vivo threedimensional analysis. Spine J 2014;14:1991-1999.

44. Ishii T, Mukai Y, Hosono N, et al. Kinematics of the cervical spine in lateral bending: In vivo three-dimensional analysis. Spine (Phila Pa 1976) 2006;31:155-160.
45. Ochia RS, Inoue N, Takatori R, Andersson GB, An HS. In vivo measurements of lumbar segmental motion during axial rotation in asymptomatic and chronic low back pain male subjects. Spine (Phila Pa 1976) 2007;32: 1394-1399.

46. Simons CJ, Cobb L, Davidson BS. A fast, accurate, and reliable reconstruction method of the lumbar spine vertebrae using positional MRI. Ann Biomed Eng 2014;42: 833-842.

47. Watanabe S, Inoue N, Yamaguchi T, etal. Three-dimensional kinematic analysis of the cervical spine after anterior cervical decompression and fusion at an adjacent level: A preliminary report. Eur Spine J 2012;2 1:946-955.

48. Zhao X, Wu ZX, Han BJ, Yan YB, Zhang Y, Lei W. Threedimensional analysis of cervical spine segmental motion in rotation. Arch Med Sci 2013;9:515-520. 